\section{Cureus}

\title{
Mediastinal Lymphangioma Revealed by 2- Dimensional Echocardiography: A Report of a Case in an Adult
}

Mehrnush Toufan $^{1}$, Nariman Nezami ${ }^{2}$, Mohammad Kazem. Tarzamni ${ }^{3}$, Sona Ghorashi ${ }^{4}$, Khashayar Khosraviani ${ }^{2}$, Babak Hajhosseini ${ }^{5}$

1. Department of Cardiology, Tabriz University of Medical Sciences 2. Drug Applied Research Center, Tabriz University of Medical Sciences 3. Department of Radiology, Tabriz University of Medical Sciences 4. Young Researchers Club, Islamic Azad University, Tabriz Branch 5. Center for Special Minimally Invasive and Robotic Surgery, Stanford University School of Medicine

$\square$ Corresponding author: Nariman Nezami,dr.nezami@gmail.com

Disclosures can be found in Additional Information at the end of the article

\section{Abstract}

Lymphangioma is a rare benign lesion; when detected in adults, it is often asymptomatic and mediastinal. We present a case of posterior mediastinal lymphangioma in an adult that was detected accidentally by echocardiography. It is the first time that echocardiography of mediastinal lymphangioma is reported along with the findings in chest X-ray, computed tomography (CT) scan, and contrast-enhanced multi-slice CT. The cystic type of lymphangioma usually shows vague intensity on CT; however, its multilocularity could be clearly demonstrated by transesophageal echocardiography (TEE).

Categories: Internal Medicine, Radiology

Keywords: mediastinum, mediastinal mass, computed tomography, echocardiography, lymphangioma

\section{Introduction}

Lymphangioma is one of the rare benign lesions originating from the lymphatic system. This lesion accounts for $0.7-4.5 \%$ of all mediastinal tumors among the adult population and occurs commonly in the superior or anterior mediastinum [1].

We present a case of posterior mediastinal lymphangioma in an adult that was detected accidentally by an echocardiograph. To the best of our knowledge, this is the first time that an initial diagnosis of mediastinal lymphangioma is made by echocardiography. This is also the first time that the radiologic findings of a mediastinal lymphangioma are reported using four different diagnostic modalities: echocardiography, chest X-ray, computed tomography (CT), and contrast-enhanced multi-slice CT.

Published 02/28/2011

\section{(๑) Copyright 2011}

Toufan et al. This is an open access article distributed under the terms of the Creative Commons Attribution License CC-BY 3.0., which permits unrestricted use, distribution, and reproduction in any medium, provided the original author and source are credited.

\section{Case Presentation}

In July of 2007, a 27-year-old male presented with occasional dyspnea for the past six months to Shahid Madani Hospital in Tabriz, Iran. Despite a benign physical examination, the patient insisted upon undergoing further radiologic evaluation for reassurance; therefore, transthoracic echocardiography (TTE) was conducted at the patient's personal request. The TTE revealed a multilobular cystic mass $(6.67 \times 7.66 \mathrm{~cm} ; 57 \mathrm{ml})$ posterolateral to the left ventricle, as well as a massive pleural effusion in left parasternal boarder. A hydatid cyst, a bronchogenic cyst, and a lymphangioma were considered as differential diagnoses. Further investigation by a 


\section{Cureus}

transesophageal echocardiography (TEE) revealed the multilobular cystic mass to be adjacent to the posterolateral region of the left ventricle (outside pericardium and attached to the adjacent pleural surface); up to the posterior side of the left atrium; involving left pulmonary veins, main pulmonary artery, and left and right pulmonary arteries; down to the pleural space; and right and anterior to the descending aorta. The mass had a venous type flow appearance with irregular septation (Figure 1).

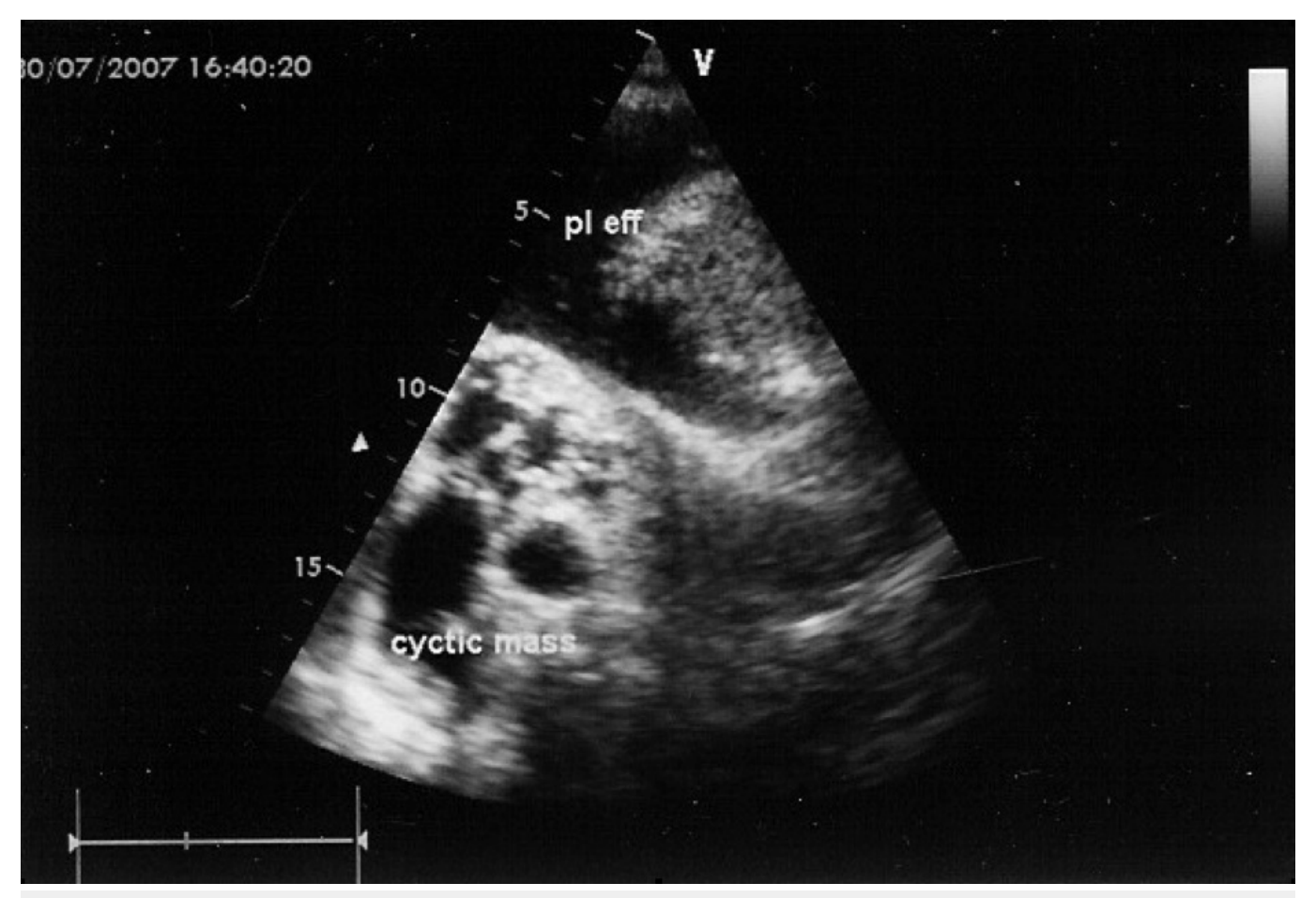

FIGURE 1: A multilobular cystic mass demonstrated by TEE, posterolateral to the left ventricle (outside pericardium), attached to the adjacent pleura.

Its size measured $6.67 \times 7.66 \mathrm{~cm}$, with the volume of $57 \mathrm{ml}$.

Patient underwent thoracentesis which showed a milky fluid. The biochemical analysis of the serum, as well as the biochemistry and cytology report of the pleural fluid is shown in Table 1. 


\section{Cureus}

\begin{tabular}{|c|c|c|c|}
\hline & Test & Level & Unit \\
\hline \multirow{4}{*}{ Serum biochemistry } & Cholesterol & 187 & $\mathrm{mg} / \mathrm{dL}$ \\
\hline & Triglycerides & 163 & $\mathrm{mg} / \mathrm{dL}$ \\
\hline & Total protein & 8.8 & $\mathrm{~g} / \mathrm{dL}$ \\
\hline & LDH & 224 & IU/L \\
\hline \multirow{6}{*}{ Pleural fluid examination } & WBC count & 3900 & $\mathrm{~mm}^{3}$ \\
\hline & Lymphocyte count & 83 & $\%$ \\
\hline & PMN & 17 & $\%$ \\
\hline & Cholesterol & 92 & $\mathrm{mg} / \mathrm{dL}$ \\
\hline & Triglycerides & 1216 & $\mathrm{mg} / \mathrm{dL}$ \\
\hline & LDH & 52 & IU/L \\
\hline
\end{tabular}

TABLE 1: Biochemical analysis of the serum, and biochemistry and cytology reports of the pleural space paracentesis.

The subsequent chest X-ray showed a pleural effusion in the left hemithorax (Figure $2 \mathrm{~A}$ ). Further study with a spiral CT scan demonstrated a normal lung (Figure 2B). Imaging by a contrast-enhanced 64-multislice CT showed a large retrocardial mass, encasing the esophagus and separated from the heart (Figure 2C)
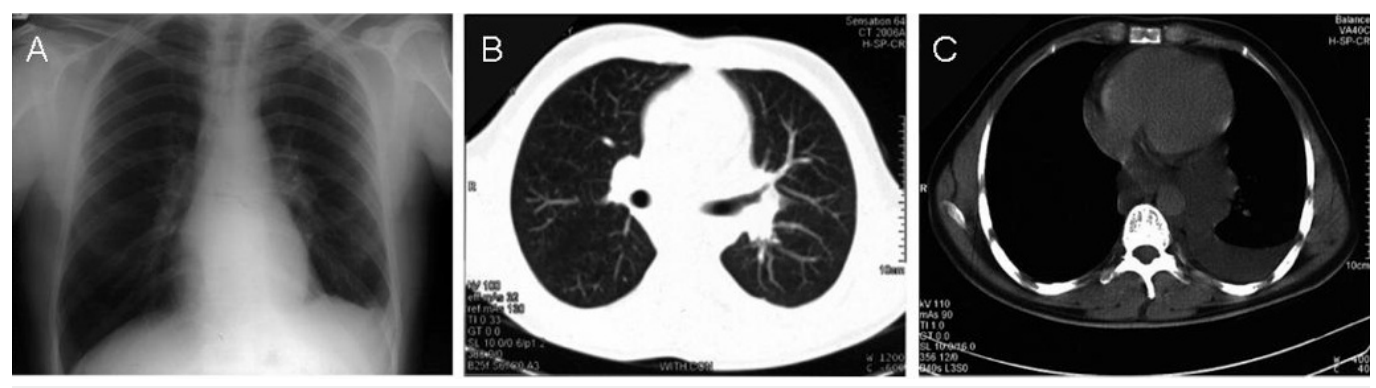

FIGURE 2: (A) Chest X-ray showed pleural effusion in the left hemithorax. (B) "Lung view" of the spiral CT demonstrated a normal lung. (C) Contrast-enhanced 64 multi-slices CT revealed a large retrocardial mass

(A) Chest X-ray showed pleural effusion in the left hemithorax. (B) "Lung view" of the spiral CT demonstrated a normal lung. (C) Contrast-enhanced 64 multi-slices CT revealed a large retrocardial mass apart from the heart, pressing against the mediastinal vessels and encasing the esophagus with low attenuation inside. 
Eventually, the diagnosis of mediastinal cystic lymphangioma was made based on the radiologic and laboratory findings. The patient did not consent to undergo any further interventions, including the surgical aspiration/resection of the cyst.

\section{Discussion}

Ninety percent of lymphangiomas manifest as a cervical or an axillary mass; the disease is more common in males [2-3]. Lymphangiomas are usually found during childhood (mainly less than two years of age), and adult cases are rare [4]. When detected in adults, they are more often mediastinal in location, and are generally asymptomatic [5]. The etiology remains unclear; however, it is suggested that dysembryogenic factors, abdominal trauma, lymphatic obstructions, or a local degeneration of some lymphatic tissues may lead to the formation of such cysts [6]. The majority of lymphangiomas are thought to be due to the congenital abnormalities of lymphatic system.

In 1828, Radenbacker first described cystic lymphangioma [7]. Traditionally and histologically, lymphangiomas are classified into simple, cavernous, and cystic types. However, according to Gerster, et al., cystic and cavernous lymphangiomas cannot be clearly differentiated [8]. The "simple" type is usually situated under the skin, and only cavernous and cystic lymphangiomas have been found intramediastinally [9]. Additionally, these tumors are usually localized in the pre-cardiovascular region of the mediastinum [4]. The distribution of lymphangioma varies. All mediastinal compartments can be affected, but anterior and superior mediastinum are the most commonly affected areas [1]. The hilum and the pericardium are rarely involved. At times, it is necessary to confirm the diagnosis or differentiate the lesion from lipoma, dermoid cyst, bronchial cyst, thyroglossal duct cyst, teratoma, salivary gland tumors, thyroid tumors, neurofibroma, or meningoencephalocele [10]. Surgical excision of localized lymphangiomas is the treatment of choice. However, surgeons often worry about the infiltrative nature of such lesions and the difficulties in achieving a complete resection [11].

In a study of five mediastinal lymphangiomas in adults, evaluation by CT revealed that all the masses had well-defined margins, showing low attenuation inside. In all cases, the masses were pressed against the mediastinal vessels, but no invasion was observed [4]. These findings were consistent with our case. In the present case, the TEE showed a cystic mass close to the posterior pericardium, and CT demonstrated a mass with multilocular appearance extended to the mediastinum. Based on the imaging findings as well as the laboratory analysis, the diagnosis of mediastinal cystic lymphangioma was made.

\section{Conclusions}

In conclusion, lymphangioma is a rare benign lesion which originates from the lymphatic system. When detected in adults, it is more often mediastinal. The cystic type usually shows vague intensity on CT imaging; however, TEE could clearly demonstrate multilocularity and help the diagnosis of the disease.

\section{Additional Information \\ Disclosures}

Human subjects: Consent was obtained by all participants in this study. Conflicts of interest: In compliance with the ICMJE uniform disclosure form, all authors declare the following:

Payment/services info: All authors have declared that no financial support was received from any organization for the submitted work. Financial relationships: All authors have declared that they have no financial relationships at present or within the previous three years with any organizations that might have an interest in the submitted work. Other relationships: All authors have declared that there are no other relationships or activities that could appear to 
have influenced the submitted work.

\section{Acknowledgements}

We are most grateful to the patients that participated in this study.

\section{References}

1. Shaffer K, Rosado-de-Christenson ML, Patz EF Jr, Young S, Farver CF: Thoracic lymphangioma in adults: CT and MR imaging features. AJR Am J Roentgenol. 1994, 162:283-289.

2. Nanson EM: Lymphangioma (cystic hygroma) of the mediastinum . J Cardiovasc Surg (Torino). 1968, 9:447-457.

3. Saijo M, Munro IR, Mancer K: Lymphangioma. A long-term follow-up study. Plast Reconstr Surg. 1975, 56:642-651.

4. Oshikiri T, Morikawa T, Jinushi E, Kawakami Y, Katoh H: Five cases of the lymphangioma of the mediastinum in adult. Ann Thorac Cardiovasc Surg. 2001, 7:103-105.

5. Shenoy SS, Barua NR, Patel AR, Culver GJ, Jennings EC: Mediastinal lymphangioma. J Surg Oncol. 1978, 10:523-528.

6. Hardin WJ, Hardy JD: Mesenteric cysts. Am J Surg. 1970, 119:640-645.

7. Rieker RJ, Quentmeier A, Weiss C, Kretzschmar U, Amann K, Mechtersheimer G, Blaeker H, Herwart OF: Cystic lymphangioma of the small-bowel mesentery: Case report and a review of the literature. Pathol Oncol Res. 2000, 6:146-148.

8. Gerster JC: Retroperitoneal chyle cysts: With especial reference to the lymphangiomata . Ann Surg. 1939, 110:389-410.

9. Henzel JH, Pories WJ, Burget DE, Smith JL: Intra-abdominal lymphangiomata. Arch Surg. 1966, 93:304-308.

10. Schloss MD, Sweet RC, Blais C, Tewfik TL: Lymphangioma in children. J Otolaryngol. 1984, 13:95-98.

11. Alqahtani A, Nguyen LT, Flageole H, Shaw K, Laberge JM: 25 years' experience with lymphangiomas in children. J Pediatr Surg. 1999, 34:1164-1168. 